articles and without comparing notes. And it would be interesting, too, to see two or more comparable journeys described by the patients who made them, or their carers, for that might show the individuality and uniqueness of each person facing the same challenge.

The $B M J$ is beginning this new series of articles for two main reasons. Firstly, this is a response to the growing recognition, certainly within the United Kingdom, that health services that have tended to focus largely on acute or life threatening illnesses must do more to improve the diagnosis, treatment, and management of chronic diseases. This is an imperative driven partly by an ageing population and a consequent increase in the incidence of chronic illness ${ }^{4}$ but also by the realisation that the quality of people's lives may be at least as important to them as the lengths of their lives.

Secondly, we hope that this new series will develop the $B M$ ss strategy to include patients in its work. Last year, with Mary Baker's assistance, the then editor, Richard Smith, established the $B M$ js advisory group for patients. This group comprises more than a dozen people representing a wide variety of patients' organisations, which provide support and information about many different diseases.

Meeting only occasionally, the group is an essentially virtual forum whose members are actively encouraged to comment on the $B M J$ and on issues affecting patients, and to become involved in the journal's work. Some of this work leads to publication, and some of it is internal and editorial. ${ }^{5}$ For instance several of the group's members have joined the weekly rota to critique each issue of the $B M J$ after publication.

This series of patient journeys will, we hope, further promote the importance of patients' voices and of narrative based medicine. We believe that doctors should be able to draw on all aspects of evidence-case based experience, the patient's individual and cultural perspectives, and the results of rigorous clinical research trials and observational studies-to reach an integrated clinical judgment. ${ }^{6}$ We will be pleased to hear your views on this first journey article and receive others co-written by any combination of patients, patient advocates, carers, and clinicians.

Peter Lapsley chief executive

Skin Care Campaign, London N19 5NA (plapsley@eczema.org)

Trish Groves senior assistant editor

$B M J$

(tgroves@bmj.com)

Competing interests: None declared.

1 Baker MG, Graham L. The journey: Parkinson's disease. BMJ 2004; 329:611-4.

Aronson JK. Autopathography: the patient's tale. BMJ 2000;321:1599602.

Huxley A. Introduction. Texts and pretexts: an anthology of commentaries. London: Chatto and Windus, 1932.

Khaw KT. How many, how old, how soon? BMJ 1999;319:1350-2.

5 Shaw J, Baker M. "Expert patient"-dream or nightmare? BMJ 2004; 328:723-4.

Greenhalgh T. Narrative based medicine: Narrative based medicine in an evidence based world. BMJ 1999;318:323-5.

\title{
Ethnic profile of the doctors in the United Kingdom
}

\section{A diverse group of doctors would appreciate the concerns of the population better}

$\overline{\text { Papersp } 597} \curvearrowleft$

The population of doctors working in the United Kingdom differs notably in ethnic profile from the wider population. Of the almost 81000 doctors employed by trusts in England in 2003, 63\% were white, $23 \%$ Asian, $4 \%$ black, $1 \%$ of mixed race, and $7 \%$ from other ethnic groups ( $2 \%$ unrecorded). ${ }^{1}$ White people make up $92 \%$ of the population of the United Kingdom. ${ }^{2}$

Two reasons exist for this difference. Firstly, the United Kingdom is a net importer of doctors, recruiting an increasing number trained in other countries, many of non-white ethnicity. Secondly, more British ethnic minority students are entering medicine. In this issue Goldacre et al show that the percentage of non-white doctors among UK graduates has increased substantially, from about $2 \%$ in 1974 to almost $30 \%$ by 2005 (p 597). ${ }^{3}$ The ethnic profile of students entering medical school is different from that of the university age population, with white men under-represented and Asian men and women over-represented. White men now comprise little more than a quarter of all medical students in the United Kingdom but $44 \%$ of the university age population. A recent study calculates a 10 -fold difference in standardised admission ratios by ethnicity. ${ }^{4}$

A difference between the population of doctors and the wider population has been clearly established with respect to ethnic profile. This is not the only dimension for which there will be differences, especially when specialties are looked at individually. There will also be a lack of mirroring across a range of other dimensions including sex, socioeconomic background, disability, religion, and sexual orientation. Does this matter, and if so, how?

One argument could be that the demographic profile of the medical workforce has never reflected that of the population served and is irrelevant. At an individual level this is a reasonable argument-patients are likely to be concerned more with the competencies of their doctors than their background. However, at the level of the entire healthcare system it is a concern if medical professionals who have great influence over policy and delivery of health care do not broadly reflect diversity in the wider population. This is because a diverse group of doctors should appreciate the concerns and priorities of the whole population better and because differences may indicate discrimination.

Does the difference in ethnic profile reflect discrimination? Sadly, evidence shows that racism continues in medicine and is experienced by patients and doctors. ${ }^{5}$ In terms of direct discrimination, students from ethnic minorities are discriminated against at entry to medical school. $^{7}$ Students from lower socioeconomic backgrounds are massively under-represented at medical school, and this is not explained by lower academic 
achievement. ${ }^{4}$ Evidence shows some self selection rooted in perceived discrimination, with able young people from lower socioeconomic groups ruling themselves out of medical school. ${ }^{8}$

Evidence also shows differential career opportunity by ethnicity. Goldacre et al show differential distributions of doctors by ethnicity by specialty. ${ }^{3}$ In part this reflects the recruitment problems in some less popular specialties (for example, psychiatry, geriatric medicine), which lead trusts to recruit doctors from abroad. Some doctors from ethnic minorities develop careers in less popular specialties because they cannot advance in their chosen area. A study of genitourinary medicine doctors in the early 1990s found that the specialty was perceived as having a low status in medicine. Many of the overseas doctors in the study would have preferred a different career (notably in obstetrics and gynaecology) but found that they could not obtain a post. ${ }^{9}$

How can we ensure that doctors in the NHS are drawn from across the United Kingdom's demographic spectrum? The number of places for medical students in the United Kingdom is being increased, and that, together with the policy of developing the roles and responsibilities of other healthcare professionals, may reduce recruitment of overseas doctors. ${ }^{10}$ Truly widening access to medical school is a challenge. A recent editorial, and the responses to it, identified a number of possible courses of action. ${ }^{11}$ The requirement for good science A levels (in particular, chemistry) restricts the pool of eligible applicants to medical school. ${ }^{12}$ More would be eligible if selection focused on overall academic ability and aptitude for practice, with opportunities to catch up on science during preclinical years. The diversity of applicants might be increased by more opportunities targeted at under-represented groups, especially those from lower socioeconomic groups. Alternative routes into medicine, such as fast track postgraduate medical training and foundation degrees aimed at other healthcare workers, could be increased.

We need to be confident that access to medical careers in all specialties is open to all with ability, aptitude, and commitment. Once this is achieved we should have a medical workforce that broadly reflects the wide diversity of the population.

Isobel Bowler independent health services researcher

90 Ranmoor Road, Sheffield S10 3HJ

(isobel@gower.u-net.com)

Competing interests: None declared.

1 Department of Health. Staff in the NHS 2003. www.publications. doh.gov.uk/public/nhsstaff2003.pdf (accessed 6 Sep 2004).

National Statistics Online. Census 2001. www.statistics.gov.uk National Statistics Online. Census 2001.
census2001/defaultasp (accessed 6 Sep 2004).

3 Goldacre MJ, Davidson JM, Lambert TW. Country of training and ethnic origin of UK doctors: database and survey studies. BMJ 2004;329:597-60. Seyan K, Greenhalgh T, Dorling D. The standardised admission ratio for measuring widening participation in medical schools: analysis of United Kingdom medical school admissions by ethnicity, socioeconomic status, and sex. BMJ 2004;328:1545-6.

5 Coker N, ed. Racism in medicine: an agenda for change. London: King's Fund, 2001.

6 Bhopal R. Racism in medicine. BMJ 2001;322:1503-4.

7 McManus IC, Richards P, Winder BC, Sproston KA, Styles V. Medical school applicants from ethnic minority groups: identifying if and when school applicants from ethnic minority groups:
they are disadvantaged. BMJ 1995;310:496-500.

8 Greenhalgh T, Seyan K, Boynton PM. "Not a university type": focus group study of social class, ethnic and sex differences in school pupils' perceptions about medical school. BMJ 2004;328:1541-4.

9 Allen I, Hogg D. Workroles and responsibilities in genitourinary medicine clinics. London: Policy Studies Institute, 1993.

10 Department of Health. Medical schools: delivering the doctors of the future. London: $\mathrm{DoH}, 2004$.

11 Hilton S, Lewis, K. Opening the doors to medicine. BMJ 2004; 328:1508-9.

12 McManus I. Medical school applications-a critical situation. BMJ 2002; 325:786-7.

\title{
Doctors and nurses with HIV and AIDS in sub-Saharan Africa
}

\author{
"We're going to run out of people before we run out of money"
}

$\mathrm{M}$ uch has been written about the impact of the HIV and AIDS pandemic on the healthcare delivery systems and resources in central and southern Africa. The unremitting pressure on hospitals and other healthcare facilities, ${ }^{1}$ and the disproportionate use of healthcare resources by the ever increasing numbers of patients, are threatening to undermine the capacity of countries such as South Africa to provide a comprehensive health safety net for the rest of the population. ${ }^{2}$

An additional threat that has received little or no attention in the literature is the possible impact of illness and death due to the pandemic specifically among healthcare professionals in countries with high HIV prevalence rates. A Medline search on this topic by using a variety of keyword combinations proved unproductive. Therefore the findings a $30 \%$ mortality over 20 years largely attributed to HIV infection among a cohort of Ugandan doctors in the article by Dambisya in this issue represent an important contribution in spite of the small numbers and the largely presumptive nature of the evidence (p 600). ${ }^{3}$

In South Africa, a country that carries $10 \%$ of the world's burden of HIV and AIDS while only $1 \%$ of the world population lives there, ${ }^{4}$ the potentially devastating impact of HIV and AIDS among health professionals on the capacity and integrity of the healthcare system is acknowledged, but only preliminary and sketchy data exist in this regard. A shortage of nurses is critical as many emigrate or succumb to AIDS related illness. Nothing is known about HIV and AIDS among doctors.

Olive Shisana and her group at the South African Human Sciences Research Council have conducted the only population based survey to date into the epidemiology of HIV in South Africa, which pegs South Africa's overall HIV prevalence in the general population (defined as those aged 2 years and older) at 11.4\% (95\% confidence interval 10.0 to 12.7$))^{5}$ These findings are in accord with the estimates by other researchers
Papers p 600

BMJ 2004;329:584-5 